\title{
Influence of Different Growing Media on Mass Production of Aschersonia aleyrodis, a Fungal Pathogen of Citrus Black Fly
}

\author{
D. N. Bhosale ${ }^{1}$, Y. V. Ingle 2* $^{\text {and H. B. Goramnagar }}{ }^{3}$ \\ ${ }^{1}$ Department of Plant Pathology, Dr. PDKV, Akola-444104, India \\ ${ }^{2}$ AICRP on Fruits, Dr. PDKV, Akola, Maharashtra, India \\ ${ }^{3}$ RFRS, Katol Dist. Nagpur, India \\ *Corresponding author
}

\section{A B S T R A C T}

\begin{tabular}{l} 
K e y w o r d s \\
$\begin{array}{l}\text { Aschersonia } \\
\text { aleyrodis, mass } \\
\text { production, growth } \\
\text { and sporulation }\end{array}$ \\
Article Info \\
$\begin{array}{l}\text { Accepted: } \\
15 \text { April } 2020 \\
\text { Available Online: } \\
10 \text { May } 2020\end{array}$ \\
\hline
\end{tabular}

Aschersonia aleyrodis (Webber) one of the fungal entomopathogens utilized as a bio-control agent and was reported as the cause of epizootics amongst citrus black fly populations. The present study was aimed to find out cost effective suitable medium for mass multiplication of Aschersonia aleyrodis. Influence of synthetic, semi-synthetic culture media and food grains as solid substrate on growth and sporulation of $A$. aleyrodis was studied under laboratory condition. Amongst the different culture media tried, Potato dextrose agar and Asthana and Hawker's media produced good growth $(9.0 \mathrm{~cm}$ and $8.90 \mathrm{~cm}$ respectively) and abundant sporulation (2.31 x $10^{6}$ and $2.12 \times 10^{6}$ spore/ml respectively) of A. aleyrodis within short span of time. Among the six food grains, sorghum as solid substrate resulted in highest spore $\left(3.40 \times 10^{7}\right.$ spore/ml) production and next best was maize (3.32 $\mathrm{x} 10^{7} \mathrm{spore} / \mathrm{ml}$ ) proved to support the production of maximum spore load of tested fungus whereas rice and barley were least preferred substrate in producing the spores $\left(1.44 \times 10^{7}\right.$ spore $/ \mathrm{ml}$ and $1.13 \times 10^{7}$ spore/ml respectively.

\section{Introduction}

Among the entomopathogenic fungi, Aschersonia aleyrodis (Webber) are important entomogenous fungi that have been found predominately in tropical and subtropical habitats and are known to be pathogenic to Aleyrodidae and Coccidae family insect pests like black fly, white fly and scale insects (Petch,1921). However, mass production of entomogenous fungi is important steps in successful utilization of entomopathogenic fungi as biocontrol agents. The production of conidia dependents upon the culture medium and its nutritional source which plays important role in determining the quantity of conidia in terms of spore germination. 
Few attempts have been made to multiply the mycopathogen using semi-synthetic media and solid substrates. $N$. rileyi has been mass produced on crushed sorghum $+1 \%$ yeast extracts (Vimala Devi and Prasad, 2003). Patel (1990) reported that sorghum was the best substrate for growth and sporulation of M. anisopliae. Bhadauria et al., (2012) reported that pea amended media produced maximum biomass of the Beauveria bassiana while Sabouraud's dextrose broth produced significantly higher spore production of the fungi. Mycelia growth and sporulation on synthetic and semi-synthetic media are essential biological characteristics of fungi, including A. aleyrodis. However, very meager information available with the nutritional requirements and mass production of Aschersonia aleyrodis. In order to further facilitate the physiological study of this fungus and its application in bio-control more information is required. The first step is to increase the biomass and sporulation in an artificial culture.

At present to promote the growth and sporulation of entomopathogens solid and liquid state fermentation procedure was adopted. Solid state fermentation was used for the production of aerial conidia (Rousson et $a l ., 1983$ ) and submerged liquid fermentation for the production of blastospores, which are short lived, and hydrophilic (Romback, 1989). However, the most viable mass production technologies include making use of a diphasic strategy in which the fungal inoculum is produced in liquid culture, which is further utilized for inoculating the solid substrate(s) for conidia production (Burges and Hussey, 1981). Therefore, the present study was undertaken to evaluate synthetic and semi synthetic culture media (solid and liquid) and food grains substrate for the mass production of Aschersonia aleyrodis to make it very cost efficient and easily adaptable with locally available indigenous substrates.

\section{Materials and Methods}

The present study was conducted in the Department of Plant Pathology, Dr. Panjabrao Deshmukh Krishi Vidyapeeth, Akola and AICRP on Fruits, Dr. PDKV, Akola. The black fly nymph that appeared to be mycosis was collected from Pala village of Morshi Tahsil of Amravati district. The mycosis insect samples brought to the laboratory and pathogen was isolated on PDA media.

\section{Multiplication on different media}

Pure culture subjected to grown on ten different solid media in Petri plates as well on broth media $(100 \mathrm{ml})$ in 250 conical flasks and incubated for 15 days in BOD at $25 \pm$ $1{ }^{\circ} \mathrm{C}$. The media used for the study were Potato dextrose agar, Sabouraud's maltose agar + yeast extract (1\%), Sabouraud's dextrose agar + yeast extract, V8 juice medium, Barley carrot yeast extract medium, Malt extract agar medium, Barner's medium, Czapek's medium, Corn meal agar and Asthana and Hawker's medium. Each treatment was replicated thrice. Observations on radial mycelia growth, average number of days required for sporulation and spore count were recorded on agar media and dry mycelia weight were recorded on broth media.

\section{Multiplication on different grain substrate}

Mass multiplication is an essential aspect for the production and commercialization of biological product. Following substrates were used for mass production. Clean and dry sorghum, wheat, bajra, maize, rice, and barely were crushed in the household mixer for about 30 second to make small pieces. Crushed grains $(100 \mathrm{~g})$ added to $250 \mathrm{ml}$ conical flask and $95 \mathrm{ml}$ sterile distilled water was added. Then soaked for $24 \mathrm{hrs}$ and autoclaved for 20 minutes at $1.04 \mathrm{~kg} / \mathrm{cm}^{2}$. After cooling, each flask was inoculated with 
$6 \mathrm{~mm}$ circular agar disc from 15 days old fungal culture grown on PDA plates, and shaken well to disperse the inoculum. The conical flaks were incubated in BOD incubator at $25 \pm 1^{\circ} \mathrm{C}$. After 15 days, fungal mass along with spores from each flask was harvested along with the substrate and crushed after drying under laminar air flow for $12 \mathrm{hr}$.

The spore powder along with grain carrier was suspended in $50 \mathrm{ml}$ sterile $0.05 \%$ Tween 80 solution and mixed thoroughly using a sterile glass rod. The suspension was filtered through Whatman No. 1 filter paper and conidial yield was counted using haemocytometer (Pandey and Kana, 2008).

\section{Statistical analysis}

The data collected from the experiments were subjected to analysis of variance for different treatments. Fisher's protected critical difference $(\mathrm{CD})$ test was used to indicate the difference between the treatments at the probability level of $p<0.01$ following the procedure described by Gomez \& Gomez (1984).

\section{Results and Discussion}

\section{Effect of different solid media on growth and sporulation of $A$. aleyrodis}

\section{Effect on radial mycelia growth}

It is evident from (Fig. 1) that significant differences were found in radial growth of $A$. aleyrodis. Almost all the media were more or less supported the growth of A. aleyrodis. Significantly more growth was noticed on PDA medium $(9.0 \mathrm{~cm})$ followed by Asthana and Hawker's media showed $8.90 \mathrm{~cm}$ radial growth. Other media viz; Barely carrot yeast extract (BCY), Barners, Czpeck's, supported the growth but all were at equal level of significance $(8.3,7.38$, and 7.22, $\mathrm{cm}$ respectively). Slow and minimum growth $(2.18 \mathrm{~cm})$ was observed in Sabouraud's dextrose agar media among the tested media.

\section{Number of days required for sporulation}

Figure 1 showed that all the ten media have expressed different performance in respect to number of days required for sporulation. PDA media was significantly effective over other media and sporulated within 8.69 days. Thereafter, Asthana and Hawker's media supported minimum days (9.49) for sporulation. Sabouraud's dextrose agar (SDA) initiated sporulation after 14.01 days.

\section{Effect of spore count}

All the ten media performed differently in exhibiting varied intensity of spore production (Fig. 1). Highest spore load to the extent of $2.31 \times 10^{6}$ spore $/ \mathrm{ml}$ of fungal suspension was obtained in PDA medium which was statistically significantly superior over all the media. Asthana and Hawkers, Czapek's, Malt extract medium also favoured for good sporulation. Least spore production $\left(1.0 \times 10^{6}\right.$ spore/ml) was observed in SDA media.

A. aleyrodis had an ability to utilize the specific substrates for their growth and multiplication. Maximum mean colony diameter, spore count and minimum number of days required for sporulation was observed on Potato dextrose agar media followed by Asthana and Hawkers media as synthetic media followed by Barley Carrot Yeast extract media as semi synthetic media.

Next effective medium was Barners, and Czpeck's medium. Minimum colony diameter, spore count and maximum days required for sporulation observed in Sabouraud's dextrose agar medium $(2.18 \mathrm{~cm}$; $1.00 \times 10^{6} \mathrm{spore} / \mathrm{ml}$ ) respectively. 
These findings resembled with the results reported by Homrahud et al., (2016) and Lima et al., (2017), who reported that PDA medium was most suitable for culturing Aschersonia. Homrahud et al., (2016) reported that Sabouraud's dextrose agar medium produced statistically less number of conidia of Aschersonia placenta than that of Potato dextrose agar and Sabouraud's maltose agar medium which is consistent with the present findings.

The main constituent of Potato dextrose agar medium is dextrose and potato which might have utilized as source of carbon resulted in profuse growth. Similarly Berger (1921) cultured A. aleyrodis on sweet potato agar and obtained higher spore load $\left(8 \times\right.$ x $10^{6}$ spore $/ \mathrm{cm}^{2}$ ).

\section{Effect of different broth media on growth and sporulation of $A$. aleyrodis}

\section{Effect on growth}

Among the ten different broth media evaluated, maximum dry mycelial weight of A. aleyrodis noted in Potato dextrose broth (Figure 2) and observed as a best supporting medium that yielded $(0.60 \mathrm{~g}))$ dry mycelial weight followed by Asthana and Hawker's broth $(0.58 \mathrm{~g})$. Other broth viz; Barley carrot yeast extract broth, Barner's and Czpeck's broth also supported the growth $(0.54,0.54$, $0.51 \mathrm{~g}$ respectively) and relatively equal level of significance.

Malt extract broth $(0.45 \mathrm{~g})$ and Sabouraud's maltose broth $(0.41 \mathrm{~g})$ showed at par level of significance. The broth V8 juice and corn meal broth showed less growth 0.24 and 0.23 $\mathrm{g}$ respectively as compare to other media. The minimum dry mycelial weight was reported on the Sabouraud's dextrose broth i.e. (0.04 g).

\section{Number of days required for sporulation}

In particular broth media number of days required for sporulation recorded to the tune of 8.52 to 14.20 days in respective media (Figure 2). Less number of days required for sporulation of Aschersonia recorded in Potato dextrose broth media i.e. 8.52 days.

Second best media was Asthana and Hawker's media influence the sporulation within 8.56 days and which is at par with barely carrot yeast extract broth (8.79 days) and Barner's media (8.92 days). Maximum number of days required for sporulation reported in SDA media (14.20 days).

\section{Effect of spore count}

Unlike solid media, broth media also exhibiting varied degree of spore production. Maximum spore count $\left(2.28 \times 10^{6}\right.$ spore/ml $)$ noted in Potato dextrose broth medium (Figure 2).

Second best medium was found Asthana and Hawker's yielded $2.17 \times 10^{6}$ spore $/ \mathrm{ml}$. Least spore production $\left(1.03 \times 10^{6}\right.$ spore $\left./ \mathrm{ml}\right)$ registered in Sabouraud's dextrose broth media.

In general Potato dextrose broth medium and Asthana and Hawker's broth medium are supporting the fungal dry biomass, minimum days for sporulation and maximum spore load. The broth like Sabouraud's dextrose have been found to be less effective in supporting dry mass and sporulation of Aschersonia.

In liquid media growth and sporulation was slow and more time required as compared to solid media. These results are in line with the earlier studies carried out by Kulat et al., (2002) and Hamrahud et al., (2016). 
Table.1 Effect of different solid media on growth and sporulation of A. aleyrodis

\begin{tabular}{|c|l|c|c|c|}
\hline $\mathbf{S N}$ & Media & $\begin{array}{c}\text { Mycelial } \\
\text { Growth in cm } \\
(\mathbf{1 0} \text { DAI })\end{array}$ & $\begin{array}{c}\text { No. of days for } \\
\text { sporulation }\end{array}$ & $\begin{array}{c}\text { Spore count } \\
\left(\times \mathbf{1 0}^{\mathbf{6}} \mathbf{s p o r} / \mathbf{m l}\right)\end{array}$ \\
\hline $\mathbf{1}$ & Potato dextrose agar & 9.00 & 8.69 & 2.31 \\
\hline $\mathbf{2}$ & Sabouraud's maltose agar & 5.72 & 11.85 & 1.25 \\
\hline $\mathbf{3}$ & Sabouraud's dextrose agar & 2.18 & 14.01 & 1.00 \\
\hline $\mathbf{4}$ & V8 juice & 3.65 & 12.26 & 1.23 \\
\hline $\mathbf{5}$ & Barely carrot yeast extract & 8.30 & 9.72 & 1.81 \\
\hline $\mathbf{6}$ & Malt extract & 6.75 & 11.12 & 1.44 \\
\hline $\mathbf{7}$ & Barners & 8.23 & 10.01 & 1.59 \\
\hline $\mathbf{8}$ & Czapek's & 8.13 & 10.08 & 1.49 \\
\hline $\mathbf{9}$ & Corn meal agar & 3.20 & 13.20 & 1.05 \\
\hline $\mathbf{1 0}$ & Asthana and Hawkers media & 8.90 & 9.49 & 2.12 \\
\hline & CD $(\mathrm{P}=0.01)$ & 0.30 & 0.031 & 0.024 \\
\hline
\end{tabular}

DAI days after inoculation

Table.2 Effect Of different broth media on growth and sporulation of A. aleyrodis

\begin{tabular}{|c|l|c|c|c|}
\hline $\mathbf{S N}$ & \multicolumn{1}{|c|}{ Media } & $\begin{array}{c}\text { Mycelial dry } \\
\text { weight } \mathbf{g} \\
(\mathbf{1 5} \text { DAI })\end{array}$ & $\begin{array}{c}\text { No. of days for } \\
\text { sporulation }\end{array}$ & $\begin{array}{c}\text { Spore count } \\
\left(\times \mathbf{1 0}^{\mathbf{6}} \mathbf{\text { spore}} \mathbf{m l}\right)\end{array}$ \\
\hline $\mathbf{1}$ & Potato dextrose broth & 0.60 & 8.52 & 2.28 \\
\hline $\mathbf{2}$ & $\begin{array}{l}\text { Sabouraud's maltose broth } \\
\text { broth }\end{array}$ & 0.41 & 11.58 & 1.25 \\
\hline $\mathbf{3}$ & Sabouraud's dextrose broth & 0.04 & 14.20 & 1.03 \\
\hline $\mathbf{4}$ & V8 juice broth & 0.24 & 13.17 & 1.20 \\
\hline $\mathbf{5}$ & $\begin{array}{l}\text { Barely carrot yeast extract } \\
\text { broth }\end{array}$ & 0.54 & 8.79 & 1.78 \\
\hline $\mathbf{6}$ & Malt extract broth & 0.45 & 9.13 & 1.39 \\
\hline $\mathbf{7}$ & Barners broth & 0.54 & 8.92 & 1.54 \\
\hline $\mathbf{8}$ & Czapek's broth & 0.51 & 9.03 & 1.48 \\
\hline $\mathbf{9}$ & Corn meal broth & 0.23 & 9.52 & 1.07 \\
\hline $\mathbf{1 0}$ & Asthana and Hawkers broth & 0.58 & 8.56 & 2.17 \\
\hline & & & & 0.0052 \\
\hline & SE(m) \pm & 0.003 & 0.024 & 0.024 \\
\hline
\end{tabular}

DAI days after inoculation 
Table.3 Effect of different food grain substrates on conidial production of A. aleyrodis

\begin{tabular}{|c|l|c|}
\hline SN & Grain substrate & Spore count 20 DAI $\left(\times \mathbf{1 0}^{\mathbf{7}} \mathbf{s p o r e} / \mathbf{m l}\right)$ \\
\hline $\mathbf{1}$ & Sorghum & 3.40 \\
\hline $\mathbf{2}$ & Maize & 3.32 \\
\hline $\mathbf{3}$ & Wheat & 3.25 \\
\hline $\mathbf{4}$ & Bajara & 2.80 \\
\hline $\mathbf{5}$ & Rice & 1.44 \\
\hline $\mathbf{6}$ & Barely & 1.13 \\
\hline & F'test & Sig. \\
\hline & SE $(\mathrm{m}) \pm$ & 0.018 \\
\cline { 2 - 3 } & CD $(\mathrm{P}=0.01)$ & 0.081 \\
\hline
\end{tabular}

*average of four replications DAI days after inoculation

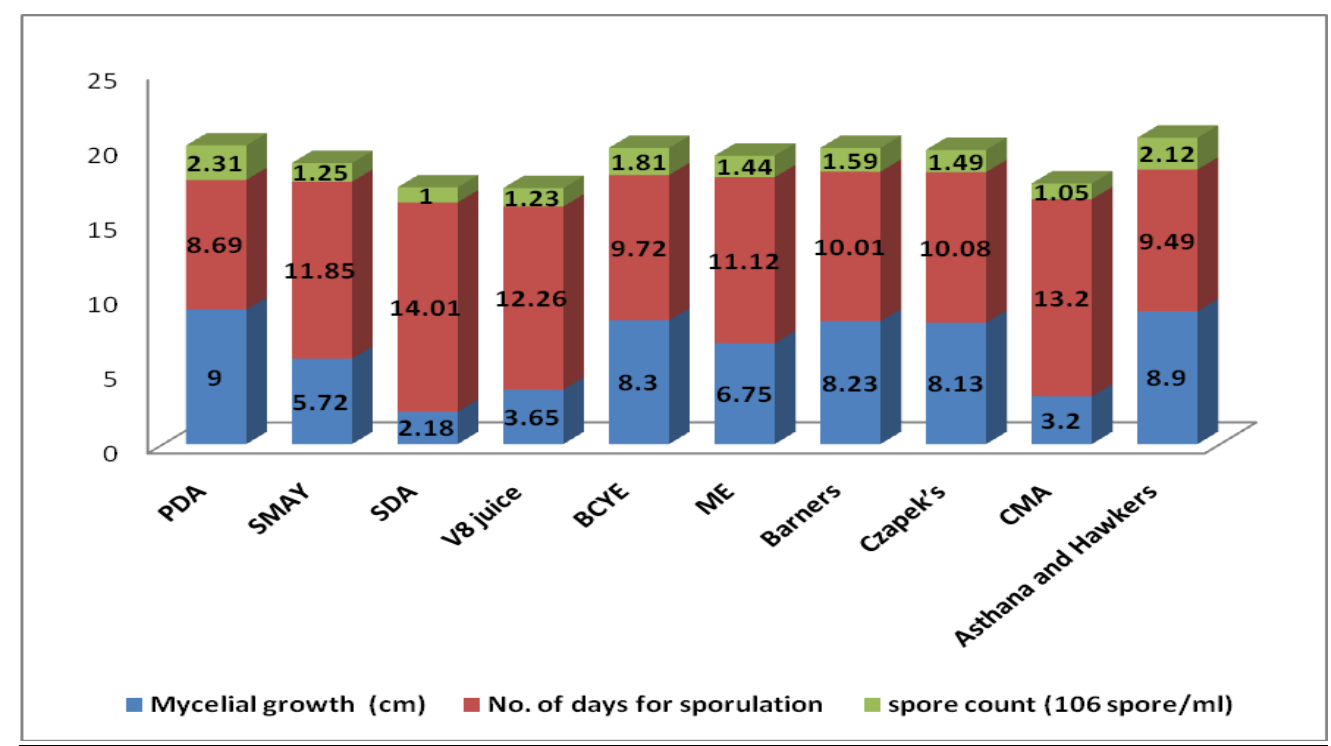

Fig.1 Effect of different solid media on growth and sporulation of A. aleyrodis

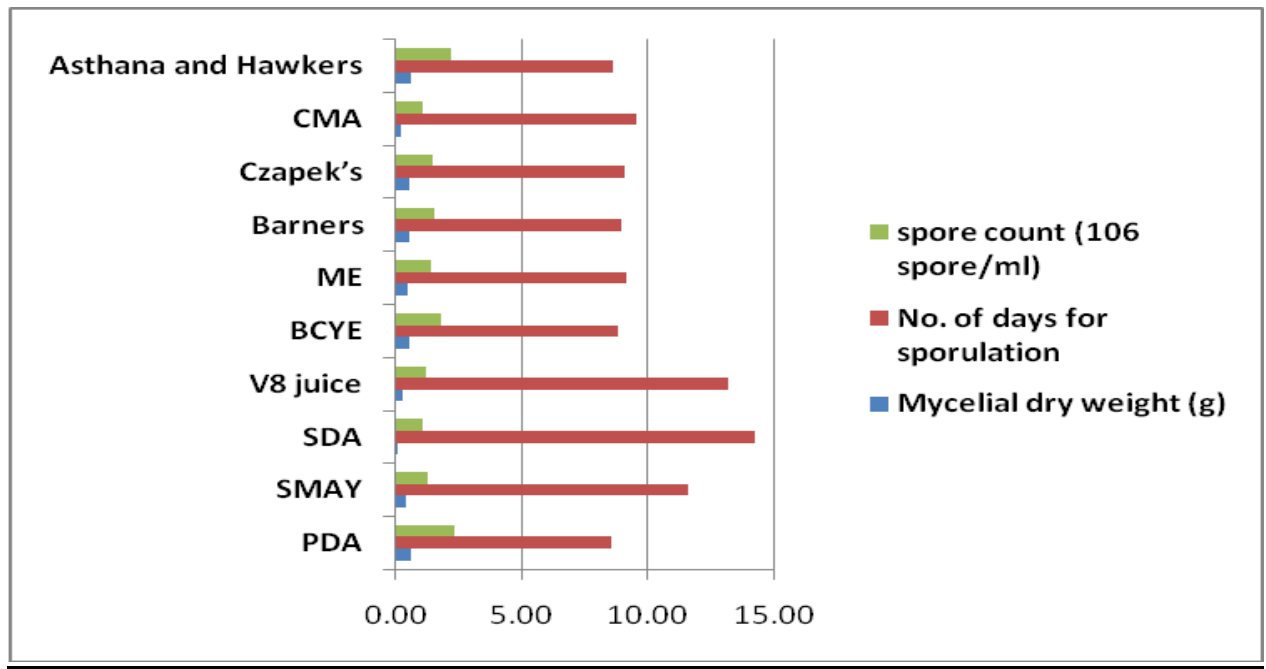

Fig.2 Effect of different broth media on growth and sporulation of A. aleyrodis 


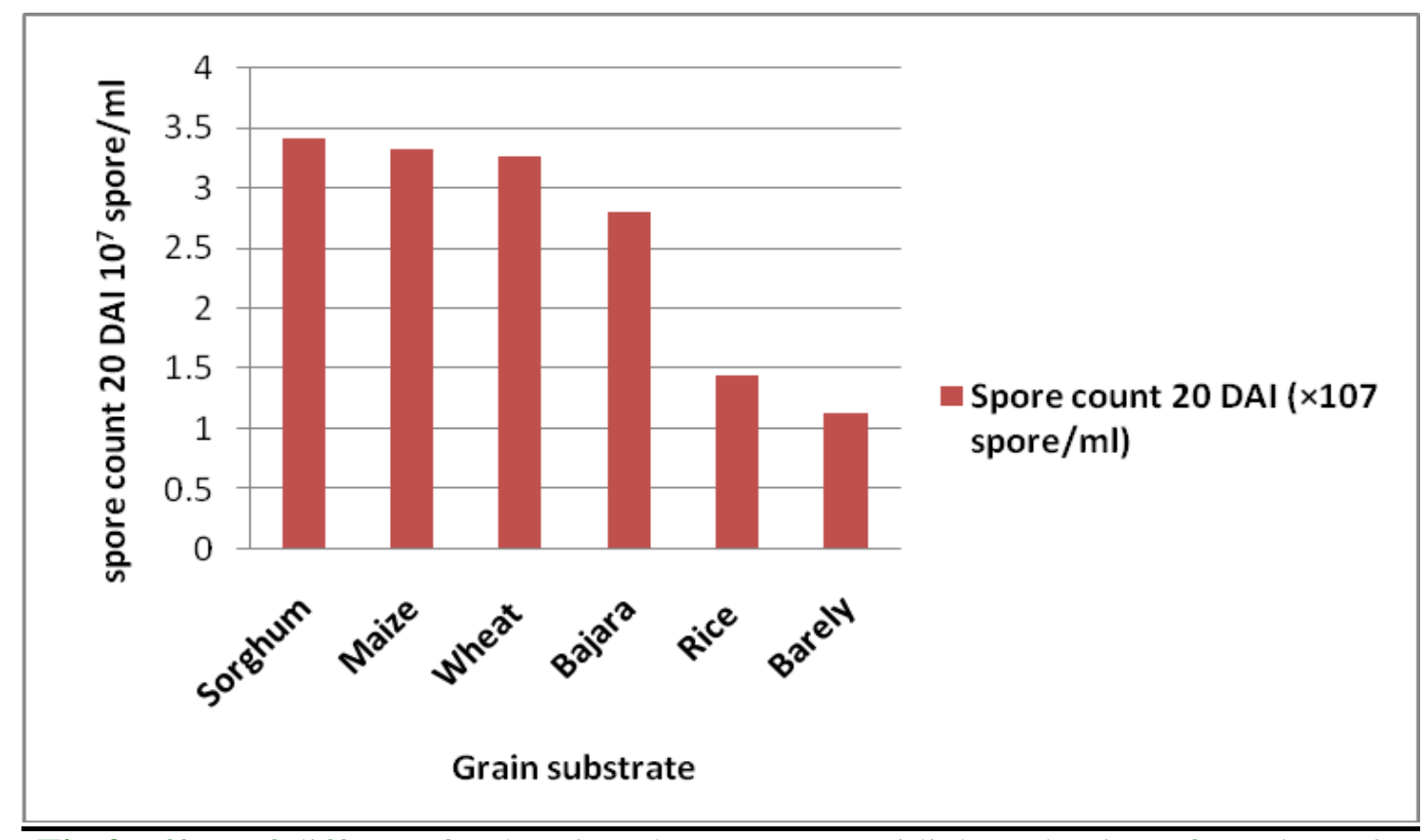

Fig.3 Effect of different food grain substrates on conidial production of A. aleyrodis

Effect of different food grain substrates on conidial production of $A$. aleyrodis

Among the grain substrates tested, sorghum $\left(3.40 \times 10^{7}\right.$ spores $\left./ \mathrm{ml}\right)$ and maize $\left(3.32 \times 10^{7}\right.$ spores $/ \mathrm{ml}$ ) were found to support the production of maximum spore load of $A$. aleyrodis. Wheat as substrate measured spore count $3.25 \times 10^{7}$ spores $/ \mathrm{ml}$ was noticed after 20 days of incubation. (Figure 3 and Plate 3 ).

Bajra also measured spore count $2.80 \times 10^{7}$ spores $/ \mathrm{ml}$ whereas rice and barely were least preferred substrate in producing the spores $1.44 \times 10^{7}$ and $1.13 \times 10^{7}$ spores $/ \mathrm{ml}$ respectively.

Previous workers have also successfully used agro-wastes such as crushed sorghum maize, wheat, rice bran, bajra and bagasse singly and along with supplementation for mass multiplication of Nomuraeya rileyi, Metarhizium, Beauveria and Parcilomyces (Vimala Devi and Prasad, 2003; Pandey and Kana, 2008; Puzari et al., 1997 and Gopalkrishnan et al., 1999). However, a perusal of literature reveals that these results might be providing information for the first time as sorghum and maize grains supported maximum sporulation of A.aleyrodis. This might be due to crushed sorghum and maize will help to provide more surface area for growth of fungus and make available substrates for hydrolyzing enzymes. Crushed sorghum proved to be a good source of soluble starch. Hydrolysis of starch in sorghum releases higher amount of glucose and maltose (Preez et al., 1985).

Moreover, sorghum grains containing higher amount of dextrose $(1.8 \%)$ and amino acids such like glutamic acid (Anonymous 1991) possibly favoured the sporulation. In particular A. aleyrodis, for mass production, solid substrate fermentation (food grains) is most admirable method as compare to artificial media. The benefit of this method is that spores are easily harvested and can be used to prepare formulations. Furthermore, their foremost advantages are use of easily available agriculture based and biodegradable substrate. This allows the cheaper and safe exploitation of this fungus in insect pest management. 


\section{Acknowledgement}

All sort of assistance rendered by ICARAICRP on Fruits scheme for the above study is gratefully acknowledged.

\section{References}

Anonymous, 1991, Hand Book of Cereal Science and Technology, (Eds. Klans, J. E. Lovenz and K. Karel). Marcel Dekkar Inc., New York. pp 175.

Berger, E. W., 1921, Natural enemies of scale insects and whiteflies in Florida. Florida. Quart. Bull. Fla. Stn. Plant Board 5, 141.

Bhaduria Bhanu Pratap, Puri, S. and Singh P. K., 2012, Mass production of entomopathogenic fungi using agricultural products. The Bioscan, 7(2):229-232.

Burges, A. D. and Hussey, N. W.,1981, Microbial Control of Insect Pests and Mite, Academic Press, London, pp. 161-167.

Gomez, K. A.and Gomez, A. A., 1984, Statistical Procedures for Agricultural Research, second ed. John Wiley and Sons, New York, NY, USA.

Gopalakrishnan, C., Anusuya, D. and Narayanan, K., 1999, In vitro production of conidia of entomopathogenic fungus Parcilomyces farinosus. Entomology. 24: 389-392.

Homrahud, D., Uraichuen S. and Attathom, T.,2016, Cultivation of Aschersonia placenta Berkeley and Broom and its efficacy for controlling Parlatoria ziziphi. Agriculture and Natural Resources, 50: 179-185.

Kulat, S. S., Zade, N. N., Peshkar, L. N. and Varhade, S. S., 2002, Influence of different culture media on the growth and sporulation of Metarhizium anisopliae (Metsch.) Sorokin. J. Biol.
Control., 16(2): $177-179$.

Lima, B.M.G.V., Almida, J.E.M., Moreira, J.O.T, Santos, L.C., Bittencourt, M.A., 2017, Entomopathogenic fingi associated with citrus black fly (Alerocanthus wogulmi) in southern Bahia. Arg. Insta. Biot., 84(1):1-3.

Pandey, K., and Kana, K. R.., 2008, Effect of different grains as solid substrates on sporulation, viability and pathogenicity of Metarhizium anisopliae (Metschnikoff) Sorokin. J. Biol. Control, 22(2): 369-374.

Patel, K. C., Yadaw, D.V., Dube, H. C.and Patel, R. J. .1990, Laboratory and mass production studies with Metarhizium anisopliae. Annu. Biol., 6: 135-138.

Pitch, T.,1921, Studies on entomopathogenic fungi: The genera Hypocrella and Aschersonia. Annals of the Royal Botanic Gardens Peradeniya, 7:167278.

Preez, J. C., Jong, F.P., Botes, J. and Lategon, T. M., 1985, Fermentation alcohol from grain sorghum starch. Biomass, 8, pp $101-117$

Puzari, K. C., Sharma, D. K. and Saranka, L. K., 1997, Media for mass production of Beauveria bassiana. J. Biol. Control, 11: 96-100.

Romback, M. C., 1989, Production of Beauveria bassinaa conidia in submerged culture. Entomophaga, 5: 45-52.

Rousson, S., Rainbautt, M., and Lonsane, B. K., 1983, Zymotics a large scale fermenter design and evaluation. Appl. Biochem. Biotechnol, 42: 161-167.

Vimala Devi and Prasad, S., 2003, Conidia production of the entomopathogenic fungus $N$. rileyi and its evaluation for control of $S$. litura on Ricinus communis. J. Invertebrate Pathology, 63:145-150. 


\section{How to cite this article:}

Bhosale. D. N., Y. V. Ingle and Goramnagar. H. B. 2020. Influence of Different Growing Media on Mass Production of Aschersonia Aleyrodis, a Fungal Pathogen of Citrus Black Fly. Int.J.Curr.Microbiol.App.Sci. 9(05): 1583-1591. doi: https://doi.org/10.20546/ijcmas.2020.905.179 